\title{
IMPLIKASI KEBERADAAN YOGA ANANDA MARGA UNIT KARANGASEM TERHADAP MASYARAKAT KARANGASEM
}

\author{
Oleh : \\ I Wayan Lali Yogantara \\ Dosen Fakultas Dharma Acarya IHDN Denpasar \\ laliyoga12@gmail.com
}

\begin{abstract}
Yoga Ananda Marga Unit Karangasem is located on Amlapura City. However, the existence of some people in the city of Amlapura has not been known until now. The study was directed to get clarity about the implications of the existence of the Yoga Ananda Marga Unit Karangasem on the Karangasem community. Data is obtained by observation, interview, documentation, and literature study methods. The results showed that the implications of the existence of the Yoga Ananda Marga Unit in Karangasem include increasing the spiritual awareness of the community by conducting yoga activities with the community both conducted at the Ashram Yoga Ananda Marga Unit Karangasem and outside the ashram, especially yoga asanas, while for fasting camp, akhanda kiirtan and prabhat samgiit exercises were carried out at the Ashram Yoga Ananda Marga Unit in Karangasem; and the implications for social behavior were reflected in the form of social assistance in the form of delivery of groceries, cash assistance, free treatment, and home surgery.
\end{abstract}

\section{Keywords: Implications, Ananda Marga Yoga}

\section{PENDAHULUAN}

Saat ini yoga merupakan gaya hidup sebagian umat manusia di dunia. Sebagai sebuah sistem, yoga adalah suatu sistem pendidikan yang terpadu antara tubuh, pikiran, dan jiwa. Yoga terbentuk dari kebudayaan India kuno dan telah dilakukan serta dikembangkan sejak 5.000 tahun yang lalu (Widya, 2015: 6-9).

Yoga Ananda Marga Unit Karangasem di bawah naungan Yayasan Yoga Parikrama Karangasem berkedudukan di Amlapura, namun hingga saat ini belum diketahui eksistensinya oleh sebagian masyarakat di Amlapura. Di samping itu, masyarakat umum belum begitu tertarik belajar yoga terkecuali yang sudah berpendidikan cukup. Sebagian besar masyarakat yang menjadi belajar pada Yoga Ananda Marga Unit Karangasem adalah pegawai negeri dan pegawaai swasta.

Di Kabupaten Karangasem ada organsasi yoga yaitu Komunitas Yoga Karangasem. Sejumlah organisasi yang punya aktivitas di antaranya belajar yoga ikut bergabung dalam Komunitas Yoga Karangasem tersebut. Mereka mengajak anggotanya untuk berlatih yoga bersama-sama dengan kalangan masyarakat Karangasem setiap hari Minggu mulai pukul 06.00 hingga 08.00 Wita bertempat di Taman Budaya Candra Bhuana Amlapura. Pelatihnya diambil dari tokohtokoh atau instruktur dari masing-masing organisasi yoga secara bergiliran. Hingga saat ini untuk penyiapan instruktur lebih didominasi oleh instruktur dari Yoga Ananda Marga Unit Karangasem. Nampaknya Yoga Ananda Marga pesertanya atau anggotanya terbanyak bila dibandingkan dengan pasraman atau ashram-ashram yoga yang lain di Karangasem. Yoga Ananda Marga Unit Karangasem yang dipimpin oleh seorang dokter di samping mengajak anggotanya berlatih yoga, juga melakukan kegiatan sosial seperti aksi kesehatan masyarakat, memberikan bantuan sosial, bedah rumah dan juga melakukan kegiatan ilmiah seperti seminar. 
Berdasarkan uraian latar belakang di atas, masalah yang ditemui adalah implikasi keberadaan Yoga Ananda Marga Unit Karangasem bagi masyarakat Karangasem. Secara umum penelitian dilakukan untuk lebih memahami keberadaan Yoga Ananda Marga Unit Karangasem dan secara khusus penelitian bertujuan untuk mendeskripsikan implikasi keberadaan Yoga Ananda Marga Unit Karangasem bagi masyarakat Karangasem.

\section{METODE PENELITIAN}

Dalam penelitian ini digunakan metode pengumpulan data seperti: (1) observasi, (2) wawancara, (3) dokumentasi, dan (4) studi pustaka (Sanjaya, 2013: 247). Analisis data dilakukan dengan mengorganisasikan data, menyusun ke dalam pola, memilah yang penting dan yang akan dipelajari, serta membuat kesimpulan yang dapat diceritakan kepada orang lain (Moelong, 2011: 247). Aktivitas dalam analisis data dilakukan melalui tiga kegiatan yaitu, data reduction, data display, dan conclusion drawing/verification (Huberman dalam Sugiyono, 2008: 246).

\section{PEMBAHASAN}

\subsection{Keberadaan Yoga Ananda Marga Unit Karangasem}

Yoga Ananda Marga Unit Karangasem terbentuk tanggal 14 September 1996. Pada awalnya pengajaran yoga dilakukan dari rumah ke rumah. Sekitar tahun 2000, seorang tokoh masyarakat, I Made Suwala meminjamkan tempat di Jalan Untung Surapati (Selatan SMAN 2 Amlapura) sebagai Sekretariat dan tempat kegiatan, sampai pertengahan tahun 2007. Pada akhir tahun 2007 sampai 2013 meminjam tempat di Puri Gede Karangasem. Sejak tahun 2013 mulai menetap di Ashram Yoga Ananada Marga Unit Karangasem yang beralamat di Lingkungan Kerta Sari, Kelurahan Padangkerta, Kecamatan Karangasem, Kabupaten Karangasem.

Yoga Ananda Marga Unit Karangasem ini bergerak di berbagai bidang kehidupan, terutama spiritual, sosial, dan pendidikan. Berbagai kegiatan yang menyentuh langsung ke masyarakat sudah dilakukan dalam kurun waktu sejak berdirinya. Namun dalam perjalanannya kegiatan yang dilakukan sempat mengalami pasang surut, dan sejak awal tahun 2004 mulai diaktifkan kembali. Untuk meningkatkan berbagai kegiatan yang dilaksanakan dan agar dapat memberikan payung hukum atas keberadaan komunitas ini, maka dibentuklah suatu yayasan yang bernama Yayasan Yoga Parikrama Karangasem.

Terkait dengan sistem perekrutan anggota baru pada Yoga Ananda Marga Unit Karangasem adalah sangat terbuka untuk umum, untuk seluruh masyarakat Karangasem tanpa membedakan suku, agama, ras, etnis atau kelas sosial masyarakat lainnya. Yang penting masyarakat dengan tulus mau bergabung dan belajar bersama sesuai ketentuan yang berlaku dalam organisasi yoga tersebut. Pembina Yoga Ananda Marga Unit Karangasem adalah Acarya yang bertugas di Karangasem, saat ini Acarya Dhyanasiddhananda Avadhuta dari India. Sedangkan Ketua Yoga Ananda Marga Unit Karangasem yaitu dr. I Ketut Budiarta.

Visi Yoga Ananda Marga Unit
Karangasem yaitu: "Mewujudkan kesejahteraan duniawi dan tercapainya kebahagiaan sejati (Atmamoksartham Jagadhitaya ca ity dharma)", sedangkan misinya adalah:

1. Mengembangkan pengetahuan spiritual serta menyebarluaskan ke seluruh masyarakat.

2. Mengadakan berbagai kegiatan sosial untuk meningkatkan rasa peduli dengan sesama serta membantu masyarakat yang membutuhkan.

3. Mengembangkan pendidikan yang menyeluruh yang menyangkut aspek pengembangan fisik, mental/intelek, dan spiritual (pendidikan neohumanisme).

Motto Yoga Ananda Marga Unit Karangasem adalah: "Sehat menyeluruh (fisik, mental, spiritual) dengan cara alami", sedangkan tujuannya adalah: 
1. Mewujudkan masyarakat yang berspiritual

2. Mewujudkan masyarakat yang peduli sosial

3. Mewujudkan neohumanisme

pendidikan aspek fisik, mental/intelek, dan spiritual)

Untuk mewujudkan tujuan tersebut maka disusun Program Kerja Yoga Ananda Marga Unit Karangasem Periode Tahun 2016 s.d 2018 sebagai berikut:

Bidang Spiritual:

1. Asanas (Senam Yoga)

2. Dharma Cakra (meditasi bersama)

3. Seminar Yoga

4. Fasting Camp (kemah puasa)

5. Akhanda Kiirtan

6. Kelas Memasak Vegetarian

7. Latihan Instruktur

8. Kelas Filsafat

9. Kelas Homeopathic dan Makanan

10. Tirthayatra

11. Latihan Prabhat Samgiit

Bidang Sosial:

1. Pembagian Sembako

2. Kunjungan ke Panti Asuhan

3. Gotong royong/Ngayah ke Pura

Bidang Pendidikan:

1. Les Mata Pelajaran dan Ketrampilan Materi pembelajaran lebih ditekankan pada yoga asanas diberikan oleh Acarya dan anggota senior yang sudah dilatih sebagai instruktur, dan untuk pengajaran meditasi diberikan oleh Acarya. Instruktur yang setiap saat melatih yoga asanas dalam kegiatan praktik yoga baik yang dilakukan di Ashram Yoga Ananda Marga dan di luar Ashram Yoga Ananda Marga adalah I Nyoman Wiraadnyana dan I Nengah Mertanu. Materi pembelajaran yoga lainnya adalah dharma cakra, fasting camp, akhanda kiirtan, dan latihan prabhat samgiit.

\section{Asanas (Senam Yoga)}

Asanas tidak dianjurkan untuk dilakukan secara tergesa-gesa karena tidak akan bermanfaat bahkan dimungkinkan dapat menyebabkan cedera. Bila ingin mendapat manfaat dari berlatih asanas maka dilakukan latihan sebanyak dua kali sehari dan dengan tubuh yang bersih dan suci (Acarya, 2001: 5556). Yoga asanas dapat memberikan manfaat yang luar biasa berkenaan dengan menjaga kesehatan, dan dapat juga menyembuhkan sejumlah penyakit fisik.

Latihan yoga asanas dapat meningkatkan kerja dari sistem tubuh, yaitu sistem saraf dan seluruh organ tubuh. Kondisi tubuh yang sehat ditunjukkan dari meningkatnya kesejahteraan secara psikologis seperti bahagia, gembira serta menurunkan gejala psikologi negatif seperti stress, cemas, dan depresi.

Yoga asanas secara rutin dilaksanakan pada hari Minggu pk. 06.00-08.00 Wita, Selasa, dan Kamis pk. 16.00-17.30, dan Jumat pk. 15.00 -16.30), bertempat di Aula Ashram Yoga Ananda Marga Unit Karangasem. Sebulan sekali dilaksanakan latihan di luar ashram tergantung situasi dan kondisi.

Untuk peserta yang baru bergabung dilatih setiap hari Jumat, dan setelah tiga kali pertemuan diperkenankan mengikuti latihan yang dilaksanakan setiap Minggu, Selasa, dan Kamis. Jenis-jenis pose asanas yang diajarkan oleh instruktur atau pelatih setiap latihan tergantung pertimbangan instrukturnya. Bila pesertanya tergolong peserta baru maka yang diajarkan adalah pose-pose yang relatif lebih mudah melakukannnya, tetapi bila yang dilatih adalah peserta yang sudah lama menjadi anggota maka materi latihannya pun cenderung yang lebih sulit. Demikian pula tidak semua pose asanas yang dilatihkan pada peserta, tergantung alokasi waktu yang tersedia. Instruktur juga mempertimbangkan agar peserta tidak cepat bosan untuk berlatih asanas yang sama dalam setiap latihan. Artinya instruktur dibolehkan untuk membuat pose-pose variatif dengan catatan pose dimaksud masih tergolong pose yoga asanas.

\section{Dharma Cakra (Meditasi Bersama)}

Untuk materi meditasi, ada 6 pelajaran yang diberikan oleh Acarya secara langsung/lisan yang bersifat rahasia/pribadi, yaitu: 
1. Iswara Pranidhana, diberikan Ista Mantra yang digunakan sebagai alat bantu untuk meditasi. Hasil yang diharapkan adalah peserta selalu dekat dengan Tuhan

2. Madhu Widya, diberikan Guru Mantra yang digunakan untuk mengawali kegiatan yang akan dilakukan, sehingga peserta tidak terikat dengan hasil dari perbuatan itu.

3. Tatwa Dharana, diberikan mantra khusus supaya peserta bisa mengontrol lima unsur yang ada dalam diri (padat, cair, api, angin, ether)

4. Pranayama, diberikan teknik pernafasan dan konsentrasi dibantu mantra khusus, untuk mengontrol prana

5. Cakra Sodhana, diberikan teknik dan mantra khusus untuk membersihkan cakra dalam diri peserta.

6. Guru Dhyana, diberikan teknik konsentrasi pada guru cakra, untuk menyatukan kesadaran diri dengan kesadaran Tuhan sehingga tercapai Samadhi.

\section{Fasting Camp (Kemah Puasa)}

Puasa dilaksanakan setiap ekadasi (hari kesebelas setelah Tilem dan Purnama. Urutan pelaksanaan puasa adalah sebagai berikut. Pagi hari minum air jeruk nipis satu gelas ditambah garam secukupnya. Puasa dilaksanakan mulai pukul 06.00 Wita hingga pukul 06.00 Wita besok paginya. Selanjutnya minum air hangat yang telah dicampur dengan 2 butir jeruk nipis ditambah 1 sendok teh garam, dijadikan tiga gelas, lalu diminum sekalian. Setelah itu jalan-jalan seputar Ashram Yoga Ananda Marga. Selanjutnya makan pisang hijau 1 buah, kelapa muda, dan bubur nasi. Setelah siang makan seperti biasa.

Praktik puasa yang dilakukan secara tulus pada hari tertentu disebut juga dengan upawasa yang bermakna selalu dekat dengan Tuhan. Orang yang telah mendapatkan inisiasi Iswara Pranidhana (pelajaran pertama) di Ashram Yoga Ananda Marga harus melakukan puasa secara teratur di semua hari ekadasi. Saat melakukan puasa tidak ada makanan yang dikonsumsi selama satu hari penuh, termasuk tidak meminum air. Bila karena situasi yang tidak dapat dihindari, seseorang tidak bisa melakukan puasa pada hari yang dijadwalkan maka ia harus melakukannya sehari sebelum atau setelah jadwal yang seharusnya. Selama sakit, puasa tidak diperlukan, namun dalam kasus demikian maka harus ada ijin dari Sekretaris Dharma Pracara Ananda Marga (khusus bagi anggota) (Anandamurti, 2005: 10).

\section{Akhanda Kiirtan}

Akhanda kiirtan dilakukan secara rutin setiap bulan pada Jumat ke-3 di Ashram Yoga Ananda Marga Unit Karangasem. Akhanda kirtan hampir sama kegiatannya dengan dharma cakra, hanya saja kiirtannya lebih lama yaitu selama 3 jam dimulai pada pukul 17.00 Wita.

Kiirtan atau kirtanam adalah memuja Tuhan dengan menyanyikan nama-nama Tuhan atau kidung suci keagamaan seperti bhajan yang bertujuan memuliakan Tuhan dan menjelaskan tentang nilai-nilai kemanusiaan. Kidung suci yang dinyanyikan dengan sungguh-sungguh dan terus menerus dapat mengantarkan manusia pada suatu kehidupan yang bahagia.

\section{Latihan Prabhat Samgiit}

Latihan prabhat samgiit secara rutin dilaksanakan setiap hari Jumat pukul 18.3019.00 Wita sekaligus mengawali kegiatan dharma cakra. prabhat samgiit adalah kumpulan lagu-lagu yang diperuntukkan bagi peserta Yoga Ananda Marga Unit Karangasem. Peserta dilatih untuk melantunkan lagu-lagu yang jumlahnya cukup banyak oleh Acarya yang sudah menguasainya.

\subsection{Implikasi Keberadaan Yoga Ananda Marga Unit Karangasem}

\subsubsection{Implikasi terhadap Peningkatan Kesadaran Spiritual}

Menurut Suryadiputra (1993: 77) kesadaran ialah tenaga yang mengalir dalam otak yang berasal dari tangkapan panca indera 
yang mengindera segala keadaan, kejadian dan peristiwa dan setiap detik mengindera keadaan, kejadian dan peristiwa yang berubah-ubah. Kesadaran menamakan diri Aku, oleh karena itu Aku sebenarnya tiap detik pula berubah. Spiritualitas adalah hubungannya dengan Tuhan, tergantung dengan kepercayaan yang dianut oleh individu dan bersifat abstrak. Yudiantara (2009: 10-12) menyimpulkan spiritual adalah berserah diri, kasih, kekosongan pikiran, kemurahan hati dan rasa syukur, keterhubungan dan keceriaan. Ini berarti bahwa spiritualitas tidak mengajarkan agar meninggalkan kehidupan dunia ini, namun lebih menekankan pada orang hidup dengan prinsip-prinsip kebebasan yang akan membuatnya bahagia dan tentram dalam menjalani hidup sebagai sebuah latihan spiritual.

Latihan yoga secara keseluruhan (asanas, meditasi, puasa, dan lain-lain) dapat meningkatkan kesehatan individu dan masyarakat. Terbukti dari respon positif para peserta, kebanyakan dari mereka yang ikut karena punya masalah kesehatan. Terbukti bagi setiap orang yang semula mempunyai keluhan suatu penyakit, dan setelah bergabung dengan Yoga Ananda Marga Unit Karangasem maka berangsur-angsur kesehatannya pulih terutama yang memiliki keluhan maag dapat diatasi dengan cara puasa, keluhan psikhis dapat diatasi dengan cara meditasi, dan tetap melakukan asanas untuk kesehatan fisik agar tetap segar bugar.

Sesuai dengan program kerja di bidang spiritual, Yoga Ananda Marga Unit Karangasem yaitu meliputi: asanas (senam yoga), dharma cakra (meditasi bersama), fasting camp (kemah puasa), akhanda kiirtan, dan latihan prabhat samgiit. Asanas (senam yoga) dilakukan bersama-sama secara rutin empat kali seminggu, yaitu Minggu, pukul 06.30 Wita, Selasa, pukul 16.00 Wita, Kamis, pukul 16.00 Wita, dan Jumat, pukul 15.00 Wita.

Untuk dharma cakra (meditasi bersama) secara rutin dilaksanakan pada hari Selasa bertempat di ashram pukul 19.00
Wita. Dharma cakra merupakan kegiatan meditasi bersama yang terdiri dari serangkaian acara yaitu menyanyikan prabhat samgiit (lagu spiritual) selama 30 menit, menyanyikan kiirtan (menyebutkan nama Tuhan) selama 30 menit, meditasi 30 menit, dan diskusi spiritual selama 30 menit. Fasting camp (kemah puasa) secara kolektif dan rutin dilakukan dua kali sebulan di Ashram Yoga Ananda Marga Unit Karangasem yang dilaksanakan pada hari Sabtu menjelang Purnama atau Tilem. Puasa dimulai pada hari Sabtu pagi dan berakhir pada hari Minggu pagi. Akhanda kiirtan dilakukan secara rutin setiap bulan pada hari Sabtu ketiga bertempat di Ashram Yoga Ananda Marga Unit karangasem. Akhanda kiirtan hampir sama kegiatannya dengan dharma cakra, hanya saja kiirtannya lebih lama yaitu selama 3 jam, dimulai pukul 17.00 Wita.

Untuk menambah pemahaman, keyakinan, dan kemantapan spiritual peserta dan masyarakat Karangasem pada umumnya, Yoga Ananda Marga Unit Karangasem melaksanakan seminar. Adapun Seminar Yoga yang dilaksanakan misalnya dengan tema "Hidup Sehat dan Bahagia Melalui Yoga" pada tanggal 14 Juni 2015 bertempat di Ashram Yoga Ananda Marga Unit Karangasem. Pada tahun yang sama juga dilaksanakan latihan instruktur dengan mendatangkan instruktur dari India dilaksanakan pada tanggal 5 Desember 2015, 19 Februari 2017 dan 19 Maret 2017. Pada tahun 2016 dilaksanakan Tirthayatra ke Pura Tanah Lot dan Batu Karu. Kegiatan dilaksanakan tepatnya pada tanggal 5 sampai 6 Mei 2016.

Dengan kegiatan yang berkaitan dengan pelaksanaan asanas, dharma cakra (meditasi bersama), fasting camp (kemah puasa), akhanda kiirtan, latihan prabhat samgiit, dan seminar yoga, diyakini dapat meningkatkan kesadaran spiritual masyarakat. Bagi kalangan peserta yang beragama Hindu akan dapat lebih meningkatkan sradha dan bhaktinya 
kehadapan Tuhan (Ida Sang Hyang Widhi Wasa).

Dengan belajar yoga, khususnya meditasi, akan meningkatkan kesadaran diri tentang hakikat kehidupan, dari mana setiap insan berasal, dan kemana tujuan hidupnya. Hal ini akan meningkatkan sradha dan bhakti baik secara individu maupun kelompok/masyarakat. Peningkatan kesadaran spiritual juga tercermin dalam aktivitas tirthayatra ke tempat suci/pura, sambil melakukan meditasi bersama dan menghaturkan punia. Dengan kedalaman pemahaman terhadap hakikat hidup sebagaimana yang diajarkan adalam Filsafat Yoga, akan terjadi kematangan spiritual yang berimplikasi terhadap intensitas aktivitas keagamaan misalnya rajin melakukan persembahyangan atau selalu termotivasi untuk mendekatkan diri kepada Tuhan.

Melakukan praktik asanas dengan tekun dan disiplin di samping dapat menyehatkan fisik, juga menyehatkan psikis dan mental. Maka bagi peserta Yoga Ananda Marga Unit Karangasem, akan siap untuk menghadapi berbagai persoalan hidup karena sudah terlatih dalam pengendalian pikiran dan indrianya melalui praktik asanas, puasa dan meditasi. Mereka akan cenderung lebih mudah melakukan kontrol diri serta fokus dalam menghadapi tantangan hidup sehingga lebih berhasil.

Kesadaran spiritual akan dapat dicapai oleh seseorang apabila pengendalian dirinya telah sempurna. Pengendalian diri bukanlah pengendalian bersifat sempurna seperti menahan marah, sedih dan sejenisnya, namun pengendalian untuk mengarahkan pikiran bersatu dengan Tuhan, dengan kebenaran yang melandasi alam semesta yang tampak dan tidak abadi ini. Maka dari itu kesadaran spiritual dapat dilaksanakan dengan jalan yoga, untuk menjernihkan pikiran serta membebaskan diri yang terbelenggu suka duka duniawi. Dengan melaksanakan yoga maka noda yang mencemarkan pikiraan perlahan-lahan menghilang dan kesadran spiritual akan muncul, menjadi tenang, menuntun orang pada kesadaran berwiweka.
Bila kesadaran spiritual seseorang telah meningkat umumnya akan terjadi perubahan terhadap suasana kebatinan seperti perasaan mendekati kebenaran, sadar akan kebiasaan buruk yang pernah dilakukan, keinginan untuk sendirian dan menjauh dari komunitas lama, tidak lagi tertarik pada halhal yang dirasa palsu dalam hidup, munculnya rasa kasih sayang terhadap orang lain yang mengalami penderitaan, besar keinginan untuk menemukan makna hidup, amat sensitif (baik intuisi, emosi, suara hati, dan inspirasi), dapat menerima diri apa adanya serta jujur. Yoga Ananda Marga Unit Karangasem berkontribusi positif dan besar terhadap peningkatan kesadaran masyarakat Karangasem pada umumnya dan khususnya pada peserta yang aktif dalam kegiatan yang dilakukan oleh Yoga Ananda Marga tersebut. Yoga Ananda Marga Unit Karangasem keberadaannya hingga saat ini berimplikasi terhadap peningkatan kesadaran spiritual masyarakat Karangasem.

\subsubsection{Implikasi terhadap Perilaku Sosial}

Psych (1988: 24) menyatakan manusia secara hakiki merupakan makhluk sosial. Sejak dilahirkan ia membutuhkan pergaulan dengan orang-orang lain untuk memenuhi kebutuan biologinya, makanan, minuman, dan lain-lainnya. Perilaku adalah merupakan perbuatan atau tindakan dan perkataan seseorang yang sifatnya dapat diamati, digambarkan dan dicatat oleh orang lain ataupun oleh orang yang melakukannya, sedangkan sosial adalah keadaan dimana terdapat kehadiran orang lain. Perilaku sosial adalah perilaku yang terjadi dalam situasi sosial, yakni saat orang berpikir, merasa dan bertindak karena kehadiran orang lain. Dapat diartikan juga sikap dimana manusia saling membutuhkan satu sama lain.

Manusia sebagai makhluk sosial berarti manusia sebagai makhluk yang memiliki dimensi kebersamaan dengan orang lain. Teori Psikoanalisa misalnya menyatakan bahwa manusia memiliki perimbangan moral sosial (super ego) ketika dihadapkan pada pilihan-pilihan berperilaku. Sedangkan ilmu 
humaniora menjelaskan realitas sosial sebagai sebuah organisme hidup dalam bentuk teoriteori sosial tentang kehidupan manusia dalam bentuk masyarakat (Latif, 2009: 4).

Menurut teori psikososial maupun teori perkembangan kognitif bahwa perilaku yang ada pada diri seseorang berlandaskan pada pertimbangan-pertimbangan moral kognitif. Selanjutnya, masalah aturan, norma, nilai, etika, akhlak dan estetika adalah hal-hal yang sering didengar dan selalu dihubungkan dengan konsep moral ketika seseorang akan menetapkan suatu keputusan perilakunya (Sjarkawi, 2009: 26).

Dalam diri setiap orang terdapat dua faktor utama yang sangat menentukan kehidupannya, yaitu fisik dan roh. Pemahaman terhadap kedua faktor ini memberikan pengaruh yang sangat besar terhadap perilaku seseorang dalam realitas kehidupannya. Kedua faktor ini memiliki ruang dan dimensi yang berbeda. Jika yang pertama adalah sesuatu yang sangat mudah untuk diindra, tampak dalam bentuk perilaku, namun pada faktor yang kedua hanya dapat dirasakan dan menentukan terhadap baik buruknya suatu perilaku (Saleh, 2012: 103).

Perilaku manusia adalah suatu fungsi dari interaksi antara individu dengan lingkungannya. Karena pada hakikatnya individu memiliki keunikan masing-masing yang membedakan satu dengan yang lain. Inilah yang disebut manusia sebagai makhluk individu. Sering orang menganggap sikap dan perilaku itu sama, padahal sebenarnya bahwa sikap dan perilaku itu berbeda. Para peneliti klasik memang mengutarakan bahwa sikap itu sama dengan perilaku, sebelum adanya penelitian terkini yang membedakan antara sikap dengan perilaku yang diprediksikan (Kusuma, 1999: 82).

Perilaku merupakan upaya individu untuk mengatur diri, menyeleksi dan memanfaatkan maupun menciptakan lingkungan yang mendukung aktivitasnya. Individu memilih, menyusun dan menciptakan lingkungan sosial dan fisik seimbang untuk mengoptimalkan pencapaian atas aktivitas yang dilakukan (Ghufron, 2011:
19). Perilaku seseorang didorong oleh motivasi. Pada titik ini motivasi menjadi daya penggerak perilaku sekaligus menjadi penentu perilaku. Motivasi juga dapat dikatakan sebagai suatu konstruk teoretis mengenai terjadinya perilaku (Saleh, 2009: 182). Perilaku juga merupakan hasil interaksi antara karakteristik kepribadian dan kondisi sosial serta kondisi fisik lingkungan. Istilah sosial memiliki arti yang berbeda-beda sesuai pemakaiannya. Istilah sosial pada ilmu sosial merujuk pada objeknya, yaitu masyarakat. Selain itu, sosial berkenaan dengan perilaku interpersonal individu, atau yang berkaitan dengan proses sosial (Supardan, 2009: 27).

Dapat dipahami bahwa perilaku sosial adalah aktivitas seseorang yang dapat diamati oleh orang lain atau instrumen penelitian terhadap suatu perangsang atau situasi yang dihadapi berkaitan dengan sosial kemasyarakatan. Perilaku sosial merupakan tindakan-tindakan yang berkaitan dengan segala perbuatan yang secara langsung berhubungan dengan nilai-nilai sosial yang ada dalam masyarakat. Bentuk-bentuk perilaku sosial misalnya menghormati orang lain, tolong menolong, sopan santun, peka dan peduli, serta berterima kasih.

Keberadaan Yoga Ananda Marga Unit Karangasem dapat diterima dengan baik oleh masyarakat dan sudah tercatat sebagai organisasi sosial di Dinas Sosial. Sering melaksanakan bakti sosial, memberikan sumbangan berupa sembako kepada masyarakat kurang mampu, bantuan kepada Pejuamg Veteran sudah menjadi rutinitas setiap perayaan HUT Kemerdekaan RI.

Pada tahun 2014 Yoga Ananda

Marga Unit Karangasem telah melakukan berbagai kegiatan sosial, seperti:

1. Pembagian sembako dirangkaikan dengan perayaan hari lahirnya Guru Shrii Shrii Ananda Murti. Kegiatan dilaksanakan di Panti Asuhan Yayasan Yasa Kerthi Karangasem, yang beralamat di Jalan Ngurah Rai Amlapura, dilakukan pada tanggal 5 Nopember 2014. 
2. Ngayah ke pura dilaksanakan secara rutin di Pura Beji Desa Pakraman Kerta Sari yang terletak bersebelahan dengan Ashram Yoga Ananda Marga Unit Karangasem. Kegiatan dilaksanakan menjelang piodalan di Pura Puseh Kerta Sari yang jatuh pada hari Raya Kuningan.

Pada tahun berikutnya yaitu tahun 2015 kegiatan di bidang sosial yang dilakukan adalah:

1. Pemberiaan beras $25 \mathrm{~kg}$ setiap tiga bulan untuk anak asuh di Puri Gede Karangasem.

2. Pemberian sembako, uang tunai dan pakaian kepada janda terlantar di Banjar Gerobog dan Banjar Bungkulan Desa Seraya pada hari Minggu tanggal 1 Maret 2015.

3. Bedah rumah, pemberian sembako dan uang tunai untuk Dadong Anom di Temega pada hari Minggu tanggal 12 April 2015.

4. Kerja sama dengan Save The Toddler Comunity melakukan kunjungan dan penyerahan sembako di PAUD Seraya Barat pada hari Jumat tanggal $21 \mathrm{Mei}$ 2015.

5. Kerja sama dengan beberapa komunitas sosial melakukan bedah rumah untuk I Wayan Nentra di Bunutan pada hari Minggu tanggal 24 Mei 2015.

6. Kerja sama dengan Save The Toddler Comunity melakukan kunjungan dan penyerahan sembako di PAUD Seraya Timur pada hari Jumat tanggal 4 Juni 2015.

7. Pemeriksaan kesehatan dan pemberian uang tunai pada keluarga tidak mampu di Budakeling pada hari Sabtu, 1 Agustus 2015.

8. Pemberian sembako dan uang tunai kepada Dadong Bunter di Banjar Sekar Gunung, Desa Bukit pada hari Minggu tanggal 2 Agustus 2015.

9. Kerja sama dengan Save The Toddler Comunity melakukan penyerahan bingkisan dan uang tunai kepada para veteran di Kecamatan Karangasem yang diserahkan setelah Upacara 17 Agustus 2015 pada hari Senin di Lapangan Ki Kopang Seraya.

10. Pemberian sembako dan uang tunai kepada I Wayan Kara dan Ni Nengah Kerti di Jasri pada hari Sabtu, 22 Agustus 2015.

11. Kerja sama dengan Puskor Hindunesia mengadakan pengobatan gratis di Banjar Kikihan dan Waliang Abang pada hari Minggu, 30 Agustus 2015.

12. Pemberian sembako dan pemeriksaan kesehatan kepada Ni Luh Kari di Banjar Tauka Tiyingtali pada hari Kamis, 3 September 2015.

13. Kerja sama dengan Puskesmas Bebandem dan IDI Cabang Karangasem melakukan pemberian sembako dan pemeriksaan kesehatan untuk Ibu Yuni di Dusun Kubu Pangi Jungutan, Karangasem pada hari Kamis, 3 September 2015.

14. Kerja sama dengan Rotary Bali Tirtagangga membagikan sembako kepada beberapa keluarga tidak mampu dan membantu bedah rumah untuk Dadong Bongol di Banjar Batu Gunung, Bukit pada hari Sabtu, 5 September 2015.

15. Kerja sama dengan relawan dari berbagai komunitas mengadakan bedah rumah untuk keluarga I Komang Gede di Banjar Kubu Pangi, Jungutan Bebandem, pada hari Minggu, 25 Oktober 2015.

16. Kerja sama dengan Yayasan Bali Kumara mengadakan program PING ( Peduli Ibu Nganggur) berupa latihan keterampilan membuat jajan di Seraya Barat, pada hari Senin-Selasa tanggal 16 dan 17 Nopember 2015.

Selanjutnya pada tahun 2016 kegiatan bidang sosial yang dilakukan adalah:

1. Bersama Prucitra Foundation mengadakan bedah rumah untuk keluarga I Wayan Misi di Munti Gunung, Kubu pada tanggal 3 Januari 2016.

2. Pemberian sembako dan uang tunai kepada warga tidak mampu di Abian Tiying, Jungutan Bebandem pada tanggal 9 Januari 2016. 
3. Bersama Yayasan Bali Kumara mengadakan penanaman seribu pohon kelapa di Seraya Timur, pada tanggal 15 Januari 2016.

4. Pemberian sembako dan uang tunai kepada Ni Luh Sari di Tista, Abang pada tanggal 15 April 2016.

5. Bersama Yayasan Bali Kumara dan Korpri Kecamatan Karangasem memberikan bingkisan dan uang tunai kepada veteran di Kecamatan Karangasem pada tanggal 17 Agustus 2016.

6. Pemberian sembako dan uang tunai kepada I Wayan Sumantara di Bukit pada tanggal 25 Desember 2016.

Pada tahun 2017 aktivitas bidang sosial yang dilakukan oleh Yoga Ananda Marga Unit Karangasem adalah:

1. Baksos pengobatan gratis tanggal $6 \mathrm{Mei}$ 2017 di Ngis Klod, Abang.

2. Penyerahan bingkisan kepada para veteran pada tanggal 17 Agustus 2017 di Kecamatan Karangasem, setelah selesai upacara bendera.

3. Pengobatan gratis di Pos Pengungsi Gunung Agung pada tanggal 6 Oktober 2017 di Ngis, Manggis.

4. Pemberian sembako kepada para pengungsi bencana Gunung Agung pada tanggal 26 Desember 2017 di Posko Pengungsi Sibetan, Karangasem.

Aktivitas sosial selama kurun waktu tiga tahun terakhir menunjukkan bahwa Yoga Ananda Marga Unit Karangasem telah melakukan aktivitas bidang sosial baik dalam bentuk bantuan sembako, uang tunai, bedah rumah, pengobatan gratis terhadap masyarakat yang membutuhkan yang ada di desa-desa di Kabupaten Karangasem. Sumber dana bantuan sosial tersebut adalah atas kerja sama dengan pihak lain seperti berbagai komunitas sosial dan juga bersumber dari urunan wajib dan donasi anggota Yoga Ananda Marga Unit Karangasem yang dipungut setiap akhir bulan. Setiap akhir bulan dipungut urunan wajib anggota masingmasing Rp 20.000 setiap anggota dan donasi yang sifatnya suka rela. Dari donasi terkumpul dana minimal Rp. 500.000 per bulan.

Yoga Ananda Marga Unit Karangasem dengan kegiatan sosial ini bermaksud ikut serta dalam mewujudkan masyarakat yang nyaman, damai, sejahtera di dunia. Hidup harmonis seperti nyaman, damai, dan sejahtera merupakan dambaan setiap orang yang normal. Membangun kehidupan bersama yang harmonis, dinamis dan produktif membutuhkan landasan filosofis yang benar, tepat, akurat dan kuat. Dengan demikian kehidupan bersama itu akan menjadi wadah setiap insan yang membutuhkan kesejahteraan dan kebahagiaan lahir batin. Dalam suatu kehidupan bersama dengan segala bentuk membutuhkan adanya seperti rasa kesetaraan, persaudaraan, dan kemerdekaan. Agama Hindu mengajarkan umatnya untuk dapat membangun diri sebagai manusia atau sebagai makhluk individu dan sosial. Membangun diri sebagai makhluk sosial adalah membangun diri untuk memahami bahwa setiap orang bisa hidup di dunia karena ada pihak lain yang saling berkontribusi sehingga hidup ini dapat berlangsung.

Mewujudkan kehidupan yang bahagia dengan melakukan hubungan yang harmonis dengan Tuhan, dengan sesama manusia dan lingkungan alam disebut dengan istilah Tri Hita Karana. Membangun hubungan yang harmonis pada Tuhan dengan bhakti, pada sesama manusia dengan dana punia (bantuan sosial) dan dengan lingkungan dengan asih (pemeliharaan alam). Implikasi Yoga Ananda Marga Unit Karangasem terhadap perilaku sosial sangat dirasakan oleh masyarakat Karangasem pada umumnya dan pihak-pihak lain yang telah dibantu pada khususnya.

\section{KESIMPULAN}

Implikasi keberadaan Yoga Ananda Marga Unit Karangasem meliputi peningkatan kesadaran spiritual masyarakat dengan melaksanakan kegiatan yoga bersama dengan masyakat baik yang dilakukan di tempat Ashram Yoga Ananda Marga Unit Karangasem maupun di luar ashram terutama 
yoga asanas, sedangkan untuk fasting camp, akhanda kirtan dan prabhat samgiit dilakukan Ashram Yoga Ananda Marga Unit Karangasem; implikasi terhadap perilaku sosial tercermin dalam wujud pemberian bantuan sosial berupa penyerahan sembako, bantuan uang tunai, pengobatan gratis, dan bedah rumah.

Bagi generasi muda khususnya generasi muda Hindu hendaknya dapat mengembangkan kompetensi diri dengan berbagai kegiatan positif termasuk belajar yoga. Bagi Yoga Ananda Marga Unit Karagasem hendaknya tetap dapat menjaga eksistensi organisasi yoga dan lebih intensip melaksanakan kegiatan terutama yang bernuansa peningkatan kesadaran spiritual dan bantuan sosial.

\section{DAFTAR PUSTAKA}

Acarya, Avadhutika Anandamitra. 2001. Yoga Untuk Kesehatan Latihan Yoga Ananda Marga untuk Pria dan Wanita. Jakarta: Persatuan Ananda Marga Indonesia.

Anandamurti, Shri Shri. 2005. Yoga Buku Panduan Yoga Sehari-hari Membahas Tuntas 42 Pose Yoga Asanas. Denpasar: Ananda Marga Caryacarya 3.

Ghufron, M. Nur. 2011. Teori-Teori Psikologi. Yogyakarta: Ar Ruzz Media.

Kusuma, Wijaya. 1999. Pengantar Psikologi. Batam: Interaksara.

Latif, Abdul. 2009. Pendidikan Berbasis Nilai Kemanusiaan. Bandung: Refika Aditama.

Moleong, Lexy J. 2011. Metodologi Penelitian Kualitatif. Bandung: PT. Remaja Rosdakarya.

Psych. W.A. Gerungan. 1988. Psikolologi Sosial. Bandung: Eresco.

Saleh, Akh. Muwafik. 2012. Membangun Karakter dengan Hati Nurani. Jakarta: Erlangga.

Sanjaya, Wina. 2013. Penelitian Pendidikan Jenis Metode dan Prosedur. Jakarta: Kencana Prenada Media Grup.

Sjarkawi. 2009. Pembentukan Kepribadian Anak; Peran Moral Intelektual,
Emosional dan Sosial sebagai Wujud Integritas Membangun Jati Diri. Jakarta: PT. Bumi Aksara,

Sugiyono. 2008. Metode Penelitian Kuantitatif Kualitatif dan $R \& D$. Bandung: Alfabeta.

Supardan. 2009. Pengantar Ilmu Sosial; Sebuah Kajian Pendekatan Struktural, Jakarta: Bumi Aksara.

Suryadiputra, R. Paryana. 1993. Alam Pikiran. Jakarta: Bumi Aksara.

Widya, Setta. 2015. Panduan Dasar Yoga. Jakarta: PT. Kawan Pustaka.

Yudiantara, I Putu. 2009. Cerdas Spiritual Melalui Bhagavad Gītā. Surabaya: Parāmita. 